\title{
Three-dimensional template-based planning for transapical aortic valve implantation
}

\author{
Stephan Jacobs, MD, PhD, ${ }^{\mathrm{a}}$ Michael Gessat, $\mathrm{PhD},{ }^{\mathrm{a}, \mathrm{b}}$ Thomas Walther, $\mathrm{MD}, \mathrm{PhD},{ }^{\mathrm{c}}$ and Volkmar Falk, MD, \\ $\mathrm{PhD},{ }^{\mathrm{a}}$ Zürich, Switzerland, and Bad Nauheim, Germany
}

Despite the lack of randomized trials comparing transapical aortic valve implantation (TA-AVI) with surgical aortic valve replacement, there is consensus that the approach may be advantageous for a high-risk group of patients. ${ }^{1,2}$ Nevertheless, several complications are associated with TA-AVI. Paravalvular leak resulting in aortic insufficiency of grade II or more is reported at a high incidence ${ }^{3}$ and promotes left ventricular dysfunction, hemolysis, and endocarditis. ${ }^{4}$ The onset of atrioventricular block (AVB) is correlated with the implantation of large-diameter valves in patients with a small annulus diameter. ${ }^{5}$

Although some of the reported complications are inherent to the procedure, others may be reduced by careful procedure planning. Three-dimensional template-based planning, as used in dental and orthopedic surgery, is proposed as an intuitive tool for this task. We present an initial retrospective patient trial of a system for 3-dimensional template-based TA-AVI planning.

\section{CLINICAL SUMMARY}

A total of 32 patients with TA-AVI (21 female, mean age 81 years) and severe aortic stenosis were selected for the study. All patients received an Edwards-Sapien implant (Edwards Lifesciences Inc, Irvine, Calif); implant sizing had been performed using computed tomography or 3-dimensional ultrasound images. Our study used preoperative data acquired from these patients for a retrograde implantation planning with a novel, 3-dimensional template-based planning system. We compared our planning results with the original implantation decisions to investigate the poten-

From the Division of Cardiac and Vascular Surgery, ${ }^{\text {a }}$ University Hospital Zürich, Zürich, Switzerland; Computer Vision Laboratory, ${ }^{\mathrm{b}}$ Swiss Federal Institute of Technology Zürich, Zürich, Switzerland; and Heart Surgery Division, ${ }^{\mathrm{c}}$ Kerckhoff Klinik, Bad Nauheim, Germany.

Development of the presented planning system was funded by the German Federal Ministry of Education and Research and the Saxon Ministry of Science and Fine Arts within the scope of the Unternehmen Region with grant numbers 03 ZIK 031 and 03 ZIK 032. This work is also sponsored by funds of the European Regional Development Fund and the state of Saxony within the framework of measures supporting the technology sector.

Disclosures: Authors have nothing to disclose with regard to commercial support.

Received for publication June 15, 2010; revisions received Sept 8, 2010; accepted for publication Sept 26, 2010; available ahead of print Nov 22, 2010.

Address for reprints: Stephan Jacobs, MD, PhD, University Hospital Zürich, Division of Cardiac and Vascular Surgery, Rämistrasse 100, 8091 Zürich, Switzerland (E-mail: stephan.jacobs@usz.ch).

J Thorac Cardiovasc Surg 2011;141:1541-3

$0022-5223 / \$ 36.00$

Copyright (c) 2011 by The American Association for Thoracic Surgery doi:10.1016/j.jtcvs.2010.09.041 tial impact of such a tool on the onset of postoperative aortic insufficiency and AVB. The procedure was blinded in the sense that no information about the actual implanted valves or the operating room outcomes influenced the planning process. The institutional review board approved use of the patient data for this work, and informed consent was obtained from the patients.

\section{Patient Modeling}

The generation and use of intraoperative DynaCT images (Syngo DynaCT; Siemens AG Healthcare Sector, Erlangen, Germany) to facilitate TA-AVI were recently described. These are 3-dimensional images reconstructed from contrast-enhanced angiography projections intraoperatively acquired with a ceiling-mounted rotation angiography system (Figure 1, $A$ ).

The 3-dimensional planning system uses these images as a basis for implantation planning. A virtual model of the aortic root is extracted (Figure 1,B). To facilitate orientation and implant registration, anatomic landmarks can be identified to indicate the position of the coronary ostia, the commissures, and the hinge points (Figure 1, $C$ ). These landmarks help the operator in identifying a cut plane through the dataset that represents the annular level on which the Sapien implant is positioned.

\section{Interactive Implant Selection}

The system automatically registers 3-dimensional templates that represent the available valve models and sizes (Edwards-Sapien 23- and 26-mm valves and Ventor Embracer [Medtronic Ventor Technologies Ltd, Netanya, Israel]) with the dataset according to the landmarks and annulus plane (Figure 1,D). The operator can switch between different valves and adjust their virtual position. In the current study, the criterion for valve selection was the valve diameter, which was optimized to exceed the mean diameter of the aortic root at the level of the valvar hinges by 1 to $2 \mathrm{~mm}$.

\section{RESULTS}

One patient died of renal and pulmonary insufficiency. Another patient had left main stem occlusion during implantation related to inadequate positioning. AVB grade III was treated with pacemaker implantation in 4 patients. Temporary symptomatic bradycardia was diagnosed in 2 patients, but pacemaker implantation was not required. Notable aortic insufficiency was diagnosed in 11 cases. 


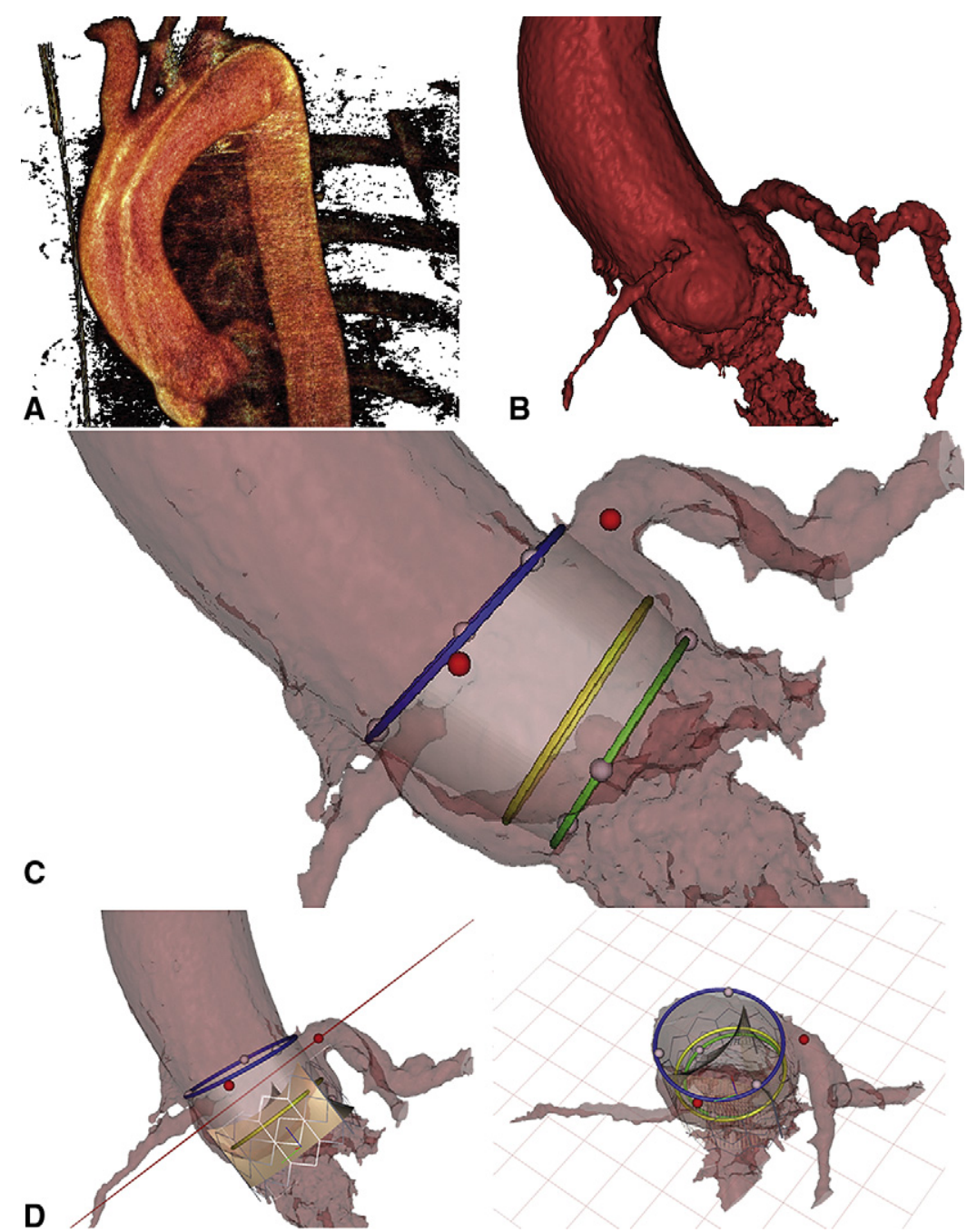

FIGURE 1. Three-dimensional template-based planning procedure: DynaCT images (A) are acquired, and patient-specific aortic root model (B) is extracted. Target landmarks are places (C), and implant templates are registered accordingly (D).

\section{Planning Results}

Figure 2 summarizes the variation between the implant selection based on 3-dimensional template-based planning and the original implant selection based on transesophageal echocardiography and computed tomography. In 17 cases, the planning decision was in accordance with the actually implanted valve size. Aortic insufficiency was seen in 3 of these cases, and 2 patients required pacemaker implantation.

In 2 cases, template-based planning promoted a $23-\mathrm{mm}$ valve in patients who had been treated with a $26-\mathrm{mm}$ valve. Both cases required permanent pacemakers to treat grade III AVBs.

In 2 cases with $23-\mathrm{mm}$ valve implants, planning recommended the implantation of a 26-mm valve. One of these patients had paravalvular leakage with mild to moderate aortic insufficiency. In the other patient, no complications were reported. In 7 patients who were treated with the $26-\mathrm{mm}$ implant, planning suggested that the $26-\mathrm{mm}$ valve

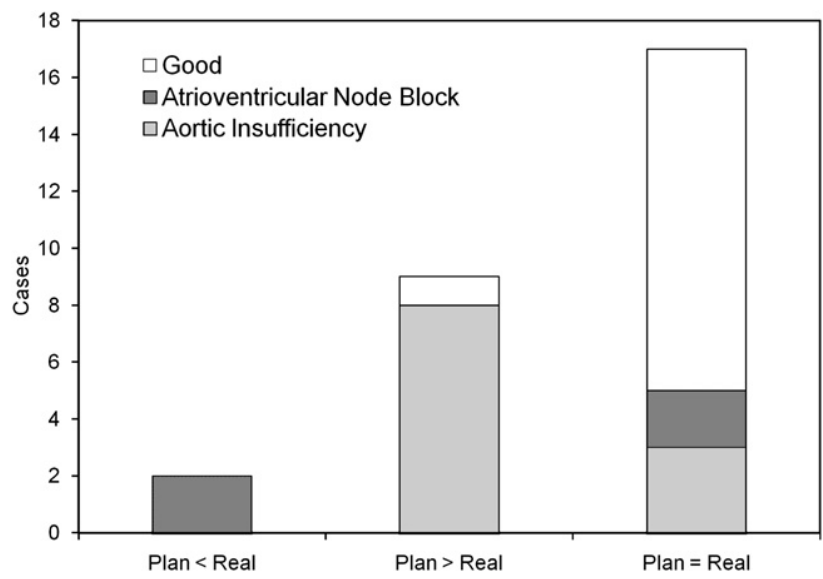

FIGURE 2. Aortic insufficiency and atrioventricular node block in patients in whom 3-dimensional planning agrees or disagrees with actual implant selection. 
(which is the largest model available) was still too small for the patient. In all 7 patients, paravalvular leak grade I or greater was found.

\section{CONCLUSIONS}

In 10 of 15 patients with postoperative $\mathrm{AI}$ or $\mathrm{AVB}$, the new system would have promoted a different valve selection. These observations suggest that the template-based planning approach is a viable aid in preoperative assessment of the atrioventricular geometry and valve selection. To substantiate the reported findings, larger studies are necessary.

\section{References}

1. Al-Attar N, Himbert D, Descoutures F, Iung B, Raffoul R, Messika-Zeitoun D et al. Transcatheter aortic valve implantation: selection strategy is crucial for outcome. Ann Thorac Surg. 2009;87:1757-63.

2. Webb JG, Altwegg L, Boone RH, Cheung A, Ye J, Lichtenstein S, et al. Transcatheter aortic valve implantation: impact on clinical and valve-related outcomes. Circulation. 2009;119:3009-16.

3. Clavel MA, Webb JG, Pibarot P, Altwegg L, Dumont E, Thompson C, et al Comparison of the hemodynamic performance of percutaneous and surgical bioprostheses for the treatment of severe aortic stenosis. J Am Coll Cardiol. 2009;53: 1983-91.

4. Walther T, Falk V. Hemodynamic evaluation of heart valve prostheses paradigm shift for transcatheter valves? J Am Coll Cardiol. 2009;53:1992-3.

5. Bleiziffer S, Ruge H, Hörer J, Hutter A, Geisbüsch S, Brockmann G, et al. Predictors for new-onset complete heart block after transcatheter aortic valve implantation. JACC Cardiovasc Interv. 2010;3:524-30.

\title{
Anterior arch translocation for coarctation of circumflex aorta using median sternotomy without cardiopulmonary bypass
}

\author{
Krishnan Ganapathy Subramaniam, MCh, Kulasekharan Marimuthu, MCh, Krishna Manohar, MCh, \\ Sudeep Verma, MD, and Kotturathu Mammen Cherian, FRACS, Chennai, India
}

The operative approach to the management of coarctation in the presence of hypoplastic circumflex, retroesophageal aorta is not well defined. ${ }^{1-3}$ We present the case of 4-year-old boy who had coarctation with hypoplastic retroesophageal arch. This was managed by translocation of hypoplastic retroesophageal arch anteriorly and creation of a left neoaortic arch through a median sternotomy without the use of cardiopulmonary bypass. We believe that median sternotomy is the approach of choice in the management of coarctation of the circumflex aorta.

\section{CLINICAL SUMMARY}

A 4-year-old boy weighing $14 \mathrm{~kg}$ had dyspnea on exertion and palpitations with increased precordial activity gradually worsening over the prior 2 years. On diagnostic workup, which included echocardiography, cardiac catheterization, and magnetic resonance angiography, he was found to have a circumflex aorta with coarctation and hypo-

\footnotetext{
From the Department of Pediatric Cardiac Surgery, Frontier Lifeline and Dr K.M.Cherian Heart Foundation, Chennai, India.

Disclosures: Authors have nothing to disclose with regard to commercial support.

Received for publication July 4, 2010; revisions received Sept 14, 2010; accepted for publication Oct 17, 2010; available ahead of print Dec 17, 2010.

Address for reprints: Krishnan Ganapathy Subramaniam, MCh, 35/1 Police Commissioners Office Rd, Egmore, Chennai-600008, India (E-mail: ganapathy subramaniamk@gmail.com).

J Thorac Cardiovasc Surg 2011;141:1543-5

$0022-5223 / \$ 36.00$

Copyright (c) 2011 by The American Association for Thoracic Surgery doi:10.1016/j.jtcvs.2010.10.020
}

plasia of the retroesophageal portion of the arch. The origin of the left subclavian artery (LSCA) was stenotic. The vessels of the ascending aorta were the left common carotid artery, the right common carotid artery, and the right subclavian artery. A coarctation was present at the base of right subclavian artery, with hypoplasia of the retroesophageal portion. A Kommerell diverticulum was present at the proximal portion of the descending aorta, which gave rise to a stenotic LSCA and a long narrow ductus. Although there was a complete vascular ring, the relatively long ductus probably did not cause any symptoms of tracheoesophageal compression (Figure 1).

We decided to approach the repair through a sternotomy. After median sternotomy and complete thymectomy, the ascending aorta, all 4 arch vessels, the patent ductus arteriosus, and the descending aorta were dissected. The descending aorta was extensively mobilized to the level of the first intercostals to achieve a tension-free anastomosis. The arch of the aorta to the right and left of the esophagus was looped as well. The patient was heparinized. The arch of the aorta at the base of right subclavian artery was transfixed and divided. The arch was mobilized from behind the esophagus. There were no vessels arising from this part of the aorta to the esophagus. The patent ductus was divided and the base of the stenotic LSCA was divided and transfixed as well. The arch was transclocated anteriorly after division of the LSCA and ductus. A side-biting clamp was applied to the ascending aorta at the base of left carotid artery. After spatulation of the arch, it was anastomosed to the side of 